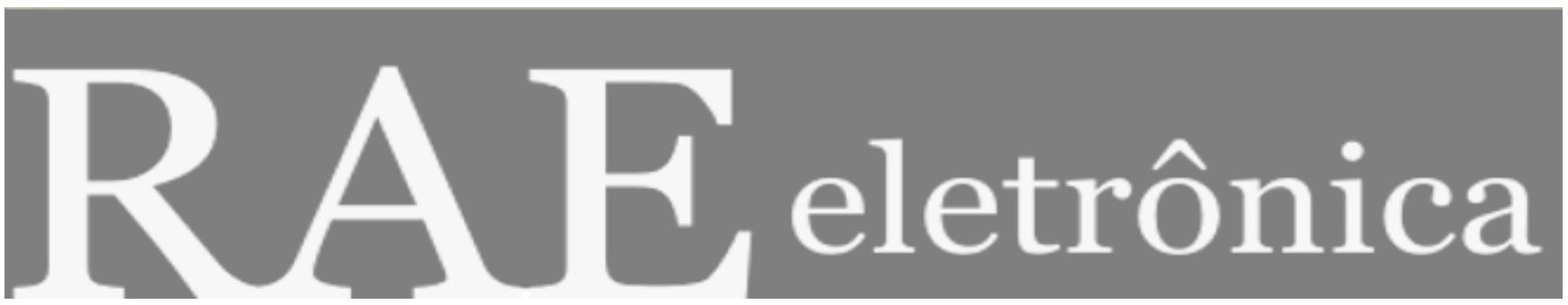

\title{
GESTÃO DO CONHECIMENTO E FORMAÇÃO CAPACIDADES EM BANCOS
}

Por:

Ricardo Uhry

Sergio Bulgacov

RAE-eletrônica, Volume 2, Número 1, jan-jun/2003.

http://www.rae.com.br/eletronica/index.cfm?FuseAction=Artigo\&ID=1296\&Secao=ORGANIZA\&Volume=2\&Numero=1 $\& A n o=2003$

CCopyright, 2002, RAE-eletrônica. Todos os direitos, inclusive de tradução, são reservados. É permitido citar parte de artigos sem autorização prévia desde que seja identificada a fonte. A reprodução total de artigos é proibida. Os artigos só devem ser usados para uso pessoal e nãocomercial. Em caso de dúvidas, consulte a redação: redacao@,rae.com.br.

A RAE-eletrônica é a revista on-line da FGV-EAESP, totalmente aberta e criada com o objetivo de agilizar a veiculação de trabalhos inéditos. Lançada em janeiro de 2002, com perfil acadêmico, é dedicada a professores, pesquisadores e estudantes. Para mais informações consulte o site www.rae.com.br/eletronica.

RAE-eletrônica

ISSN 1676-5648

(C)2002 Editora: Fundação Getulio Vargas - Escola de Administração de Empresas de São Paulo.

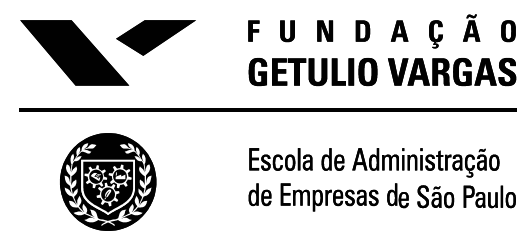




\section{GESTÃO DO CONHECIMENTO E FORMAÇÃO CAPACIDADES EM BANCOS}

Ricardo Uhry

Mestre em Administração pelo CEPPAD/UFPR e Professor da Universidade Católica de Brasília, Upis e Faculdade Millennium.

E-mail: ricardo_uhry@yahoo.com.br

Endereço: SQN 314 Bloco A, ap. 323 A. Norte Brasília - DF, 70767-010

Interesses de Pesquisa: Estratégias organizacionais, gestão do conhecimento, comunicação, organizacional e inovação.

\section{Sergio Bulgacov}

Doutor em Administração pela FGV-EAESP. Professor do Departamento de Administração -CEPPAD da UFPR

E-mail:bulgacov@ceppad.ufpr.br

Endereço: UFPR - Departamento de Administração - Rua Prefeito Lothário Meissner, 3400 Jardim

Botânico - Curitiba- Pr, 80210-170

Interesses de pesquisa: administração estratégica e teoria da complexidade.

\section{RESUMO}

Este estudo correlaciona práticas de gestão estratégica do conhecimento organizacional de três instituições bancárias com a formação de suas capacidades diferenciais. $\mathrm{O}$ método de pesquisa foi o estudo comparativo de casos, com análise descritivo-qualitativa de bancos: um estatal brasileiro, um privado brasileiro e um privado multinacional. Os resultados demonstram que gestão do conhecimento não é algo novo, mas parte de práticas já existentes. As práticas de gestão estratégica do conhecimento das organizações bancárias estudadas contribuem com a formação de capacidades diferenciais. A "concepção estratégica do negócio" é a menos evidenciada das capacidades porque persiste visão gerencial muito voltada ao orçamento, próxima da administração por objetivos. Há ações para a administração de competências. Ao salientar as diferentes proposições de valor dos bancos, mapas estratégicos representam avanço na gestão do conhecimento. A pesquisa corrobora as conclusões de estudo no qual um grupo integra o processo de construção de competências à estratégia corporativa.

\section{ABSTRACT}

This study examines the relationship between strategic management practices of organizational knowledge of three banking institutions comprising their capability differentials. The research method employed was a comparative case study among public, national private and international banks. The results demonstrated that: rather than being something new, knowledge management is rooted in existing practices. The practices of strategic management of organizational knowledge in the banking organizations studied contributed to the development of capability differentials. Due to a persisting view of management closely tied to the tactic-operational budget, not unlike that of Management by Objectives, the "strategic view of business" was the least evidenced of the capacity differentials. Practices were employed to manage competence. Strategic maps represent an advance and allow strategies and different customer-value propositions of the banks to be highlighted. The research corroborated the findings of a previous study in which a group integrated its corporate strategy into the competence-building process.

\section{PALAVRAS-CHAVE}

Setor bancário; gestão estratégica do conhecimento organizacional; capacidades diferenciais. 
ORGANIZAÇÕES - GESTÃO DO CONHECIMENTO E FORMAÇÃO DAS CAPACIDADES EM BANCOS

Ricardo Uhry - Sergio Bulgacov

\section{KEY WORDS}

Bank industry; strategic management of organizational knowledge; capability differentials. 


\section{CONTEXTUALIZAÇÃO}

As organizações vêm se deparando com um ambiente competitivo cercado de incertezas e que é afetado pela globalização, hipercompetição, volatilidade da informação, mudanças demográficas, valorização do conhecimento, entre outras questões. A base da competição se volta para a criação e assimilação do conhecimento (Porter, 1998), sendo o conhecimento considerado a "única vantagem competitiva sustentável" (Geus, 1998) e a nova base da riqueza (Thurow, 1999).

Nesse contexto, as organizações buscam a produção de conhecimento que agregue valor. O maior desafio não é só compartilhar conhecimento de forma que venha a ser incorporado a bens e serviços nesse ambiente de descontinuidade, mas principalmente desenvolver atividades facilitadoras para a criação de conhecimento e que se transformem em vantagem competitiva que permita se posicionar à frente de outras organizações.

O mais difícil parece ser sustentar tal vantagem, ou mesmo administrar deliberadamente tal processo, algo a que se poderia chamar de gestão estratégica do conhecimento organizacional. Alguns autores (Wiig, 1993; von Krogh, Ichijo e Nonaka, 2001) defendem que tal gestão resulta em vantagem competitiva. Wiig (1993 e 1998) menciona as funções de ênfase para potencializar os benefícios dessa gestão:

- FUNÇÕES ESTRATÉGICAS: procurar estratégias centradas no conhecimento, monitorar e facilitar as atividades de gestão do conhecimento, localizar, implementar incentivos para motivar a criação, compartilhamento e uso do conhecimento;

- FUNÇÕES DE ASSESSORIA: estabelecer e atualizar a infra-estrutura do conhecimento;

- FUNÇÕES OPERACIONAIS: criar, renovar, construir e organizar ativos de conhecimento, descobrir e inovar constantemente;

- FUNÇÕES DE REALIZAÇÃO DO VALOR DO CONHECIMENTO: compartilhar e aplicar os ativos de conhecimento.

Wiig (1998) também explicita atividades e possíveis benefícios às empresas:

\section{ATIVIDADES}

- Apoiar trabalhadores de linha:

- aumentar e facilitar acesso ao conhecimento.

- Obter e codificar especialização ou conhecimento específico dos trabalhadores-chave:

- aprimoramento da compreensão e relevância da especialização;

- incrementar criação e compartilhamento do conhecimento especializado;

- renovação e remoção mais efetiva do conhecimento.

\section{BENEFÍCIOS}

- Sob o enfoque de operações:

- profissionais inteligentes e motivados para usar o conhecimento;

- aprimorar a reutilização da tecnologia e das lições apreendidas;

- baixar custos operacionais e diminuir erros operacionais; 
- tomadas de decisão mais rápidas, menor tempo do projeto à produção;

- Sob o enfoque em produtos e serviços:

- Maior compreensão dos produtos e serviços de que o cliente necessita;

- produtos e serviços que melhor se ajustam às necessidades do cliente;

- produtos e serviço de melhor qualidade;

- respostas e entregas mais rápidas de produtos e serviços.

- Enfoque do cliente e do mercado:

- valor incrementado de produtos e serviços para fidelizar o cliente;

- incrementar a satisfação do cliente;

- incrementar a demanda de produtos e serviços;

- aprimorar relações entre cliente e empresa;

Assim, tais ações teriam, na visão de Wiig (1998), como resultado: boa imagem no mercado, lucratividade e viabilidade da empresa, boas relações com empregados, comunidade e sociedade, o que se constitui vantagem competitiva. Para von Krogh, Ichijo e Nonaka (2001), os programas de gestão do conhecimento obtêm como resultado minimização dos riscos, prospecção de eficiência e inovação. Adiante se indicam ainda outras concepções.

\section{OBJETIVOS DO ESTUDO}

Ante tal contextualização, procura-se identificar neste estudo como práticas de gestão estratégica do conhecimento podem ser correlacionadas com a formação de capacidades diferenciais que contribuem com o alcance da vantagem competitiva sustentável. Os objetivos específicos são:

a) Identificar as práticas de gestão estratégica do conhecimento, verificando que características se aproximam de constructos teóricos e aplicações.

b) Verificar se as práticas de gestão estratégica do conhecimento podem ser correlacionadas à formação de capacidades diferenciais.

c) Analisar e comparar as diferentes estratégias de gestão do conhecimento e sua relação com a formação de capacidades diferenciais.

d) Identificar as capacidades diferenciais que dependem de pessoas, verificando como acontece sua formação (capacidades) nas três organizações bancárias pesquisadas.

A contribuição teórica a que se propõe é correlacionar, nos três casos estudados, a gestão estratégica do conhecimento com a formação das capacidades diferenciais. Em revisão de literatura de gestão estratégica do conhecimento, Uhry (2001) identificou quinze diferentes abordagens e as classificou em dois blocos:

- Constructos teóricos: 1) capital humano, 2) ativos intangíveis, capital intelectual, 3) recursos intangíveis, 4) ativos estratégicos; 5) competências essências; 6) empresa inteligente, 7) organizações de aprendizagem.

- Aplicações: 8) modelo de gestão do conhecimento, 9) geração e difusão do conhecimento, 10) conhecimento e tecnologias de informação, 11) conhecimento por meio de universidades corporativas, 12) mensuração do conhecimento, 13) conversação e cooperação, 14) sistemas de 
aprendizagem, 15) geração e difusão do conhecimento por meio do desenvolvimento de aptidões estratégicas.

Embora exista grande volume de publicações (em muitas das quais se destacam os benefícios), ainda não está claro se a gestão do conhecimento efetivamente traz contribuições para as organizações e para a administração de suas estratégias corporativas e que possa efetivamente ser correlacionado com capacidades que constituam vantagem competitiva.

Por outro lado, a falta de gerenciamento do conhecimento também pode ser um fator de risco, podendo causar prejuízos, conforme constataram Probst e Knaese (1998) ao enfocarem como se proteger das perdas de conhecimento em análise do contexto bancário suíço e alemão. Apontam razões pelas quais os bancos devem gerenciar o risco relacionado ao know how. Além dessa abordagem, há estudo sobre o risco financeiro e a necessidade de gerenciamento estratégico do conhecimento (Marshall, Prusak e Shpillberg, 1997).

A seguir conceituam-se as definições-chave relacionadas aos objetivos do trabalho.

\section{FUNDAMENTAÇÃO TEÓRICO-EMPÍRICA}

O principal conceito refere-se à gestão do conhecimento e pode ser visto como processo por meio do qual o conhecimento é criado, difundido e incorporado aos produtos, serviços ou sistemas (Nonaka e Takeuchi, 1997), de acordo com quem o processo de gestão do conhecimento é dinâmico e envolve socialização, externalização, combinação e interiorização ou internalização.

A gestão estratégica envolve o conhecimento que pode ser gerido desde o nível corporativo até o funcional, refletindo-se também no desempenho que pode ser correlacionado com capacidades diferenciais, que são as que contribuem com a sustentação da vantagem competitiva (Hall, 1998 e 1999).

Sobre a questão do conhecimento organizacional, consta-se que não há consenso sobre o conceito, dada a diferença nos pressupostos epistemológicos de cada autor. Na concepção de von Krogh e Ross (1995) e Venzin, von Krogh e Ross (1998) há três abordagens epistemológicas distintas:

- $\quad$ Cognitivista: conhecimento é uma entidade fixa e representável (dados), universalmente armazenada em computadores, bancos de dados e manuais. Conhecimento pode ser facilmente compartilhado por toda a organização.

- Conexionista: conhecimento reside nas conexões entre especialistas e é orientado à solução de problemas. Conhecimento depende da rede de comunicações, sendo necessário interconectar seus componentes.

- $\quad$ Autopoiética: conhecimento reside na mente, no corpo e nos sistemas sociais.

Conhecimento é dependente do observador e da história, sensível ao contexto e não sendo diretamente compartilhado, somente de forma indireta por meio de discussões.

Em outra ótica, Zahn, Foschiani e Tilebein (2000) propõem que um trabalho bem feito, decorrente de vantagem proporcionada por competência, indicaria a integração do conhecimento à estratégia de negócio. 
O que leva a uma questão principal: se as capacidades são a manifestação da integração do conhecimento e se constituem no principal papel da empresa (Grant, 1999; Zahn, Foschiani e Tilebein, 2000), como verificar se a gestão estratégica do conhecimento pode ser correlacionada à formação de capacidades diferenciais?

Em princípio, basta correlacionar a gestão do conhecimento a qualquer capacidade diferencial que dependesse de pessoas. Entretanto, optou-se, para efeito desta investigação, por utilizar o conceito de capacidades diferenciais (Hall, 1998 e 1999) enriquecido, na explicitação das capacidades, principalmente pelas noções de empresa inteligente (McGill \& Slocum, 1995; Pinchot \& Pinchot, 1995).

As capacidades diferenciais a seguir podem, assim, servir como balizadores de possíveis efeitos de iniciativas associadas ao gerenciamento do conhecimento:

\section{Concepção estratégica do negócio.}

Esta capacidade diferencial funcional relaciona-se a conhecimento, habilidade e experiência dos funcionários com relação ao mercado, concorrentes, fornecedores, distribuidores, ou à concepção estratégica do processo de negócios (Hall, 1998 e 1999). Chiesa e Manzini (1997, p. 197) também colocam no primeiro nível de importância a capacidade "visão sistêmica: identificar e compreender o contexto competitivo e o quadro de referência de suas ações", que envolve a análise do contexto em que a empresa compete e a coordenação e integração dos recursos da firma. Para Davenport e Prusak (1998, p. 203) a concepção da empresa como um sistema é uma das formas de começar a gestão do conhecimento. McGill e Slocum (1995) apontam o pensamento sistêmico como um dos comportamentos da empresa inteligente.

Entretanto, visão estratégica é competência que não deve se restringir à cúpula da organização, mas integrar as competências individuais (Zarifian, 1999). Sintetizando a posição de vários autores, Fleury \& Fleury (2000, p. 25) referem-se à visão estratégica como:

conhecer o negócio, o ambiente interno e externo da empresa, identificando oportunidades, ameaças, pontos fortes e fracos. Ter clareza e comprometimento sobre objetivos e valores e auxiliar os demais profissionais na descoberta do significado de sua área de atividade, suas responsabilidades e contribuições esperadas. Identificar a necessidade de mudanças e as competências necessárias para enfrentar os desafios do negócio.

\section{Intenção estratégica de aprender.}

A habilidade para aprender é uma capacidade diferencial cultural (Hall, 1999). Davenport e Prusak (1998, p. 203) relacionam entre as formas de começar a gestão do conhecimento "construir e facilitar comunidades de aprendizado e práticas". A intenção estratégica de aprender é um objetivo e é, em princípio, aceito pelos funcionários, que o "percebem como inerentemente válido"; implica, portanto, noção de "destino, direção, descoberta" (Hamel e Prahalad, 1997, p. 150). Para McGill e Slocum (1995) a intenção estratégica de aprender pode estar relacionada a abertura a outras perspectivas, empowerment, diminuição de controles, aceitação responsável de riscos, disposição para experimentar, aceitar fracassos e aprender com o passado e abertura para o feedback. Aprender a aprender também é mencionado por Meister (1999) e está incluído no conceito de abertura de McGill e Slocum (1995), e na rede de aprendizado voluntário de Pinchot e Pinchot (1995). É o que Davenport e Prusak (1998, p. 203) consideram "concentrar-se em questões de desenvolvimento pessoal". 


\section{Compreensão e apoio às necessidades do cliente.}

Reputação da companhia e dos produtos/ serviços é o que Hall (1998 e 1999) cita como capacidades diferenciais posicionais e percepção de qualidade inclui nas capacidades culturais, entre as quais está também tradição de serviços aos clientes. Está contido em empatia referida por McGill e Slocum (1995, p. 22), definida como "resolver positivamente falhas nas comunicações, perda de confiança e dissolução de relacionamentos". Na estratégia de Intimidade com o Cliente (Treacy e Wiersema, 1995, p. 151), as "empresas íntimas dos clientes bem-sucedidas são aquelas que se tornaram peritas nos negócios de seus clientes e na criação de soluções. [...] Profundo conhecimento do cliente [...] e se moldar às necessidades destes".

Sivula, Bosch e Elfring (1998) desenvolvem modelo de gerenciamento do conhecimento específico ao negócio de empresas de serviços em que a construção da competência incorpora a dimensão dos clientes à base de conhecimentos organizacionais. Prahalad e Ramaswamy (2000) abordam a necessidade de cooptar as competências do cliente, criando-se uma rede avançada que os inclua, considerando-os agentes ativos da criação de valor e propondo a criação de uma infra-estrutura que permita apreender as expectativas dos clientes e até mesmo tê-los como colaboradores no desenvolvimento conjunto de produtos e serviços.

\section{Colaboração do pessoal para a inovação.}

Hall (1998) cita habilidade para inovar entre as capacidades culturais. Rede de trabalho é citada por Hall (1999) como capacidade diferencial posicional que pode servir como meio de os empregados contribuírem para a inovação. McGill e Slocum (1995) referem-se à criatividade; Meister (1999), ao raciocínio criativo e à resolução de problemas. Para Treacy e Wiersema (1995, p. 144), "[...] todos os funcionários se dedicam a repassar informações sobre o desempenho interno e externo da empresa", o que pode contribuir na busca da liderança em produtos.

\section{Utilização inteligente da base de dados.}

Hall (1999) inclui entre as capacidades diferenciais posicionais a base de dados, na qual se acrescenta a forma de utilizar os dados, que está relacionada com pessoas. Davenport e Prusak (1998, p. 53-54) referem-se ao uso da "Tecnologia de Informação com sabedoria: [...] a informação agrega valor e não se observam as seguintes limitações: estruturas rígidas de dados, de difícil consulta, concentração excessiva no sistema e desleixe no conteúdo, sobrecarga de informações, lentidão no sistema". Schuck (1997, p. 239) descreve "o principal papel dos funcionários [...] usar as informações de modo a contribuir para o negócio". 


\section{METODOLOGIA}

A seguir sintetiza-se o que foi denominado Gestão Estratégica do Conhecimento Organizacional, buscando-se esclarecer a correlação com as Capacidades Diferenciais, por meio do quadro das categorias analíticas sintetizadas no quadro $\mathrm{n}^{\mathrm{o}} 1$ :

\begin{tabular}{|l|l|}
\hline Gestão Estratégica do Conhecimento: & Capacidades Diferenciais: \\
\hline $\begin{array}{l}\text { Gestão do Conhecimento integrada à } \\
\text { estratégia: }\end{array}$ & $\begin{array}{l}\text { Concepção estratégica do negócio: } \\
\text { Conhecimento dos } \\
\text { Quais são as estratégias }\end{array}$ \\
$\begin{array}{c}\text { distribuidores } \\
\text { relacionadas à gestão do conhecimento? } \\
\text { Onde e como são geridas? }\end{array}$ & $\begin{array}{l}\text { Intenão estratégica de aprender: } \\
\text { Habilidade para aprender }\end{array}$ \\
Como se dá a criação, aplicação e & Compreensão e apoio às necessidades do cliente: \\
compartilhamento do conhecimento no & Reputação da empresa e do serviço; Empatia \\
contexto de negócios? & Contribuição para a inovação: \\
Qual o modelo teórico adotado? & Habilidade para inovar; \\
& Contribuições por meio de rede. \\
& Utilização inteligente da base de dados: \\
& Usar as informações de modo a contribuir para o negócio \\
\hline
\end{tabular}

Quadro $n^{\circ} 1$ : Gestão Estratégica do Conhecimento $\Leftrightarrow$ Capacidades Diferenciais

\section{DELIMITAÇÃO E DESIGN DA PESQUISA}

Opta-se por uma abordagem de estudo de caso comparativo explicativo ou causal ex post factum com corte transversal, com estratégia de pesquisa qualitativa. O nível de análise é organizacional e as unidades de análise são compostas de indivíduos dirigentes dos subgrupos operacional e estratégico das três organizações em estudo.

As organizações estudadas foram escolhidas intencionalmente entre as doze maiores do sistema bancário. Além de intensiva em serviços e conhecimento, a indústria bancária é um elemento no jogo pela determinação da competitividade de um país, por permitir reunir e canalizar recursos excedentes para as atividades produtivas, ou dissipá-los em atividades especulativas. O setor, no Brasil, vem passando por transformações, marcadas pela entrada de bancos estrangeiros e por aquisições/liquidações de bancos estaduais e dos que apresentavam fragilidade financeira (Carvalho, 1999).

Nesse contexto, o critério de escolha foi a diferença da constituição do capital dos bancos e sua representatividade percentual no mercado bancário brasileiro: $10,8 \%$;

BANCO 1: público nacional, segmento que representa $45 \%$ (incluindo-se o BNDES, com

BANCO 2: privado nacional, segmento que representa $31,5 \%$;

BANCO 3: privado estrangeiro, segmento que representa $23,5 \%$.

Pelo critério de ativos totais, com relação ao sistema bancário como um todo, os doze maiores do ranking concentram 74,9\% do mercado (incluindo-se o BNDES). Destes, os bancos privados detêm 23,8\% do setor; os bancos públicos, 25\% (excluindo-se o BNDES); os bancos de capital estrangeiro têm 15,3\% de participação no sistema (fonte: Banco Central do Brasil, dados de dezembro 2001). 
As entrevistas foram com dirigentes dos subgrupos operacional e estratégico das organizações sob estudo. Foram entrevistados 22 indivíduos: 11 do nível operacional de agências na cidade de Curitiba e 11 do nível estratégico, incluindo o presidente de um dos bancos.

A coleta de dados deu-se por meio de (1) dados secundários: utilização de documentos; (2) dados primários: informações colhidas com indivíduos em entrevistas semi-estruturadas em profundidade, para as quais são utilizados os dados secundários e a observação não participante. E, buscando-se maior rigor metodológico, um esquema teórico serviu como princípio diretor da coleta de dados (Bruyne, 1977). No tratamento dos dados, foram utilizadas: pesquisa documental, análise documental, análise do discurso e análise de conteúdo, o que foi complementado com a técnica de triangulação dos dados.

\section{LIMITAÇÕES DO ESTUDO}

As limitações decorrem do fato de que fatores relacionados à gestão estratégica do conhecimento e às capacidades diferenciais dependem do levantamento de opiniões por meio de entrevistas, que estão sujeitas às inferências subjetivas porque baseadas no que "o analista compreende da significação da mensagem" (Bardin, 1979, p. 115).

Para atenuar tal limitação, foi adotado o cuidado de não tornar a pesquisa dependente apenas de informantes-chave (Yin, 1989) e "reler o material, alterar releituras e interpretações e desconfiar da evidência" (Bardin, 1979, p. 115), valendo-se da técnica de triangulação e da observação não participante. Outras limitações são inerentes ao fato de as organizações serem escolhidas por conveniência e se restrigir ao universo de três empresas.

Procurou-se minimizar as limitações com os melhores procedimentos recomendados para tal tipo de pesquisa. Além disso, a representividade é ampla para permitir a busca de esclarecimentos com relação à realidade a ser observada, dentro da opção metodológica escolhida.

\section{CONSTATAÇÕES A PARTIR DA ANÁLISE E COMPARAÇÃO DOS DADOS}

Quanto à estratégia explícita do Banco 1, há semelhança com a que a American Productivity \& Quality Center APQC (1996) cita como gestão do conhecimento enquanto estratégia de negócio, em que o conhecimento está sempre sendo aprimorado e disponível às pessoas. Entretanto, quando analisados os dados, constata-se que a estratégia efetiva é mais responsabilidade pessoal por conhecimento, ou seja, incentivo ao aprendizado. Na visão de Hansen, Nohria e Tierney (1999), está próximo da abordagem da personalização, pessoa a pessoa, incentivando-se especialização e investindo-se em tecnologias voltadas à Web, e moderadamente em banco de dados.

O Banco 1 utiliza uma adaptação do balanced scorecard (Kaplan e Norton, 1997) no seu sistema de avaliação de desempenho, acompanhado pela Unidade de Recursos Humanos, com os indicadores de mensuração geridos também pelas unidades de Controladoria, Estratégia, Marketing e Comunicação e Controles Internos. Todos funcionários são avaliados anualmente e recebem uma participação nos lucros, proporcional ao escore balanceado atingido no sistema. São estabelecidas metas e criados fatores de acompanhamento do desempenho, sob cinco perspectivas: 1) estratégia e operações, 2) resultados econômicos, 3) processos internos, 4) clima organizacional e 5) pesquisa de satisfação do cliente.

No Banco 1, a implementação iniciou com a última etapa, o sistema de recompensas, sendo o gestão do desempenho mais um instrumento de mensuração dos objetivos, não diretamente alinhado à 
estratégia da organização. "A introdução do balanced scorecard somente para recompensa" é considerada por Kaplan e Norton (2001, p. 361) uma falha na implementação do processo.

Não se verifica que o sistema de avaliação de desempenho valorize contribuições ao banco de conhecimentos, à inovação, ou outra prática referida na literatura de gestão do conhecimento (Davenport e Prusak, 1998). Assim, a gestão do desempenho não parece diretamente relacionada com um modelo de gestão de conhecimento, muito menos articulada com as formas de mensuração do capital intelectual aludidas por Stewart (1998), sugerindo falta de alinhamento de estratégias no Banco 1.

O Banco 2 aparentemente não tem um programa pró-ativo de gestão do conhecimento, não sendo possível identificar um modelo teórico. Apesar disso, foram identificadas muitas práticas, pois gestão de conhecimento "baseia-se em recursos existentes" (Davenport e Prusak, 1998, p. 196): boas práticas de gestão de recursos humanos, que podem ser o ponto de partida para gerir o conhecimento.

A abordagem à gestão do conhecimento do Banco 2 pode ser enquadrada como personalização, pessoa a pessoa, incentivando-se a especialização (Hansen, Nohria e Tierney, 1999). É o que Angeloni e Fernandes (2000, p. 6) abordam como a dimensão pessoas, que envolve aprendizagem, compartilhamento e inovação, e também a dimensão infra-estrutura, que engloba visão holística, cultura, estilo gerencial - "que possibilitem a flexibilidade, a comunicação e a participação das pessoas". Pontos fortes na cultura de carreira fechada do Banco 2, que incentiva a inovação com iniciativas como o programa Boas Idéias e Soluções e a socialização do conhecimento entre empregados e clientes. Na tipologia da American Productivity \& Quality Center APQC (1996) trata-se de inovação e criação do conhecimento.

A noção de conhecimento do Banco 2 se aproxima um pouco da linha conexionista, pois o conhecimento está voltado à ação e reside nas conexões entre os empregados. Na tipologia de Nonaka e Takeuchi (1997), de forma semelhante aos banco 1 e 3, o Banco 2 adota um modelo organizacional hierárquico do topo para a base, no qual a gerência média ocupa papel de processador de informações. $\mathrm{O}$ armazenamento do conhecimento é feito por meio dos bancos de dados, o conhecimento acumulado é o explícito. Entretanto, há certa influência da abordagem de baixo para cima, por haver valorização do indivíduo empreendedor, para o qual a alta gerência funciona como patrocinadora/mentora, embora as demais condições citadas por Nonaka e Takeuchi (1997) não sejam observadas.

O Banco 3 tem um programa de gestão pró-ativa. Muitas práticas foram identificadas: boa gestão do sistema de informações, de mensuração e de recursos humanos, ponto de partida para gerir o conhecimento (Davenport e Prusak, 1998, p. 196). As ações acontecem sob responsabilidade de diferentes diretorias (Tecnologia, Qualidade, Recursos Humanos) e o balanced scorecard parece servir de elo integrador a uma empresa que introjetou a cultura da qualidade.

Além disso, "existe a gestão do conhecimento, das soluções, que são implementadas e distribuídas a nível mundial", mas as soluções não são geridas na sede, em Nova Iorque, antes dependendo "da inteligência e capacidade" das filiais de diferentes países para desenvolver projetos inovadores e compartilhar com os demais. Evidencia-se que a empresa cria um espaço de compartilhamento "Ba" virtual, de combinação, criação e compartilhamento de conhecimentos de bases e realidades diferentes, com cooperação de filiais de diferentes países (grupo-a-grupo), de dimensão sistêmica, por meio de equipes de trabalho (Nonaka e Konno, 1998). O que indica certa ligação com a epistemológica conexionista. 
O Banco 3 adota a abordagem da codificação (Hansen, Nohria e Tierney, 1999), estratégia de gestão de conhecimento baseada em banco ou armazém de dados, que permite utilização inteligente, válido para o conhecimento explícito. Empenha-se por alta qualidade e confiabilidade do sistema de informações para usar o conhecimento sistematizado. A forma é funcionário acessando dado/informação nos sistemas eletrônicos que codificam, armazenam, disseminam e permitem a reutilização de dado, informação, investindo-se muito em tecnologias de informação e contando com as contribuições dos empregados para lançar mais dados no sistema.

A área de tecnologia é o que Davenport e Prusak (1998, p. 199) citam como a mais usual forma de dar o primeiro passo na gestão do conhecimento: instalam ferramenta de groupware e intranet e depois "começam a buscar conteúdo para distribuir". O que é referido por Stewart (1998, p. 100) como formas de acumular "estoques de conhecimentos sob o pretexto de gestão do conhecimento".

No Banco 3, o armazenamento do conhecimento é feito por meio dos bancos de dados, o conhecimento acumulado é o explícito (Nonaka e Takeuchi, 1997). Aparentemente não há gestão próativa do conhecimento tácito, nem exemplo de externalização. A organização atribui aos gerentes de relacionamento a tarefa de repassar as necessidades dos clientes (socialização) para área de qualidade/gerência de inovação. Das estratégias da American Productivity \& Quality Center APQC (1996), as ações do Banco 3 estão mais relacionadas com a do conhecimento focado no cliente.

\section{CONSTATAÇÕES SOBRE GESTÃO ESTRATÉGICA DO CONHECIMENTO}

Quais são as estratégias relacionadas à gestão do conhecimento, onde e como são geridas? A gestão do processo estratégico é diferente em cada organização. No Banco 1, por exemplo, salienta-se a área de Recursos Humanos com a gestão do treinamento, o programa Profissionalização, a gestão do desempenho e outras práticas que se refletem no contexto de negócios. Tais ações não são, entretanto, configuradas com outras ações identificadas, como o Programa de Qualidade e o Banco Responde, por exemplo, indicando que poderia haver melhor alinhamento de estratégias. No Banco 2, o treinamento também é a principal ação e está muito voltado à realidade de negócios. Já no Banco 3, nota-se que as práticas identificadas e integradas no contexto de negócio e geridas pelas áreas de Qualidade $e$ Tecnologia são alinhadas com ações de marketing, por exemplo. Assim, evidencia-se a integração de algumas práticas ao contexto de negócio e algum alinhamento estratégico, destacando-se o Banco 3 entre as três organizações estudadas.

Como se dá a criação, aplicação e compartilhamento do conhecimento no contexto de negócios? Nos três bancos o compartilhamento do conhecimento explícito acontece principalmente por meio de bancos de dados. No Banco 2, destaca-se a disposição do pessoal do nível operacional para contribuir com a criação de novo conhecimento, por meio de sugestões, e a socialização do conhecimento tácito, sem que aparentemente haja um processo deliberado de gestão. No Banco 1, salienta-se a socialização por meio da rede colegiada, em que gerentes compartilham seu conhecimento tácito. No Banco 3, foi referida a interação dos gerentes de relacionamento com os clientes como oportunidade para a criação de conhecimento.

Qual o modelo teórico adotado? O Banco 1 tem um modelo teórico de gestão do conhecimento no papel, que aparentemente não orienta as ações estratégicas, não contribui com a promoção do alinhamento, a configuração das ações relacionadas com gestão do conhecimento, nem se reflete na prática dos gerentes de agência. A não ser como informação sobre o assunto. $\mathrm{O}$ que não quer dizer que teorias não embasem as práticas, mas que ações de treinamento têm um referencial teórico, as de avaliação, com base no balanced scorecard, outro. Ambas as práticas não são articuladas por constructo teórico. No Banco 3, o balanced scorecard pode configurar as diferentes práticas, mas não 
foi possível constatar se é realmente o que acontece, não sendo percebido, no nível operacional, como um modelo de gestão do conhecimento. Em suma, no Banco 3 destaca-se prática que é embasada num constructo relacionado com gestão do conhecimento. Assim, nos bancos 1 e 3 pode-se admitir que há alguma forma de teorização relacionada com gestão do conhecimento. Já no Banco 2 não foi possível constatar modelo teórico, apesar de se constatar práticas.

Também merecem consideração algumas proposições de Wiig (1998) para se gerir o conhecimento:

1) Criar um banco do conhecimento: não ficou evidenciado nos bancos estudados. $\mathrm{O}$ que ficou mais próximo foi o Banco 3 que, por meio da intranet, disponibiliza palestras aos funcionários.

2) Desenvolver competência múltipla de criar e transferir conhecimento por meio de treinamento: os três bancos desenvolvem práticas bem sucedidas neste sentido.

3) Implementar incentivos para motivar a participação de todos, com idéias e inovações, na criação de novos produtos e serviços, na busca do aprimoramento dos processos e na adoção das melhores práticas, não apenas motivando a criação, mas também o compartilhamento e o uso do conhecimento. Uma abordagem tão completa não foi constatada. O Banco 2 incentiva a participação para a inovação. O Banco 3 tem uma proposta interessante de gestão da inovação, adota as melhores práticas entre as filiais de todo o mundo e interiorizou uma cultura organizacional em que se destaca a qualidade.

4) Supervisionar estrategicamente a gestão dos ativos de conhecimento: não constatado em nenhum dos três bancos.

\section{CONSTATAÇÕES SOBRE GESTÃO DO CONHECIMENTO E FORMAÇÃO DE CAPACIDADES DIFERENCIAIS}

As práticas relacionadas com gestão do conhecimento que são desenvolvidas pelos bancos 1,2 e 3 que colaboram mais com a formação de capacidades são: "compreensão e apoio às necessidades do cliente, utilização inteligente de base de dados e intenção estratégica de aprender" e as que estão menos correlacionadas são "contribuição do pessoal à inovação e concepção estratégica do negócio".

A colaboração do pessoal à inovação é mais visível no nível operacional do Banco 2. Embora o Banco 3 tenha um processo corporativo de gestão da inovação que merece destaque, não se salienta, no entanto, pela contribuição dos empregados, no nível operacional. No Banco 1 não foi possível evidenciar nem contribuições do pessoal e nem gestão da inovação.

Quanto à concepção estratégica do negócio, foi possível perceber que práticas relacionadas à gestão do conhecimento contribuem com a construção desta capacidade, que fícou, no entanto, menos evidenciada que as demais. O que permite sugerir que a visão operacional dos gerentes de agência, de curto prazo, muito voltada aos resultados imediatos, à busca de objetivos, esteja dificultando a formação da visão estratégica do negócio. Aparentemente a prática gerencial se aproxima da administração por objetivos (Drucker, 1962) que, 55 anos depois de lançada, continua forte. A ponto de, referindo-se a The Practice of Management, Lalane (1998, p. 37) indagar: "o que foi inventado depois disso?"

Para Kaplan e Norton (2001, p, 13), na maioria das organizações a prática gerencial se resume ao orçamento e a um plano para atender as discrepâncias com relação às previsões, mas frisa que não pode se resumir a isso, propondo que se enfoque a estratégia, que deve se tornar um processo contínuo. Kaplan e Norton (2000) propõem que, constatando-se problemas com a estratégia, se utilize os mapas estratégicos. Tais mapas são apresentados em quatro níveis, partindo-se da base (4) para o topo (1) do modelo: 
4) perspectiva da aprendizagem e do crescimento, que envolve 4.1) competências, 4.2) tecnologia e 4.3) cultura corporativa, que vão influenciar a

3) perspectiva dos processos internos: 3.1) construção do privilégio (franchise) por meio da inovação, 3.2) incremento do valor para o cliente por meio do gerenciamento de processos, 3.3) alavancagem da excelência operacional por meio de processos operacionais e logísticos e 3.4) tornar-se um bom cidadão corporativo, que vão afetar a

2) perspectiva do cliente, baseado nas proposições de valor 2.1) excelência operacional, 2.2) intimidade com o cliente e 2.3) liderança em produtos (Treacy e Wiersema, 1995), que vão se ligar à

1) perspectiva financeira, em que:

- a construção do privilégio e

- o incremento de valor ao cliente contribuem com a 1.1.1) estratégia de crescimento da receita;

- o aprimoramento da estrutura de custos e

- a utilização dos ativos vão determinar a 1.1.2) estratégia de produtividade.

As estratégias de crescimento da receita e de produtividade vão determinar o 1.1) aprimoramento do valor para o acionista.

Aprofundando o conceito, Kaplan e Norton (2001) propuseram a idéia da organização focada na estratégia, baseada nas idéias de alinhamento e foco, e embasada nos princípios de 1) traduzir a estratégia em termos operacionais, 2) alinhar a organização com a estratégia, 3) tornar a estratégia uma tarefa cotidiana de todos, 4) torná-la um processo contínuo, 5) mobilizar a mudança por meio da liderança.

Ao propor mapas estratégicos, o modelo de Kaplan e Norton $(2000,2001)$ representa avanço com relação à proposta anterior do balanced scorecard. Foram traçados mapas para as três organizações estudadas (figuras 1, 2 e 3), nos quais se constatam diferentes proposições de valor:

1) Excelência operacional, para o Banco 1, apoiada por práticas de gestão de conhecimento que destacam capacidades diferenciais como intenção estratégica de aprender e compreensão e apoio às necessidades do cliente. Na dimensão de aprendizado e crescimento, evidencia-se cultura voltada ao aprendizado, atualmente medida por pesquisa de clima. Pode envolver ainda questões como empowerment, direcionamento ao empreendedorismo, busca de contribuição para inovação, que ficam como sugestões. A construção das competências ainda precisa ser aprimorada, assim como a contribuição da tecnologia. 




\section{Figura n. ${ }^{\circ} 1$ Mapa estratégico do Banco 1}

2) Liderança em produtos, para o Banco 2, destacando-se capacidades diferenciais como colaboração do pessoal para a inovação e compreensão e apoio às necessidades do cliente. $\mathrm{Na}$ dimensão de aprendizado e crescimento, ressalta cultura voltada à socialização, incentivada por ações que buscam as contribuições para a melhoria dos produtos, serviços e processos. O processo de construção de competências e a contribuição da tecnologia podem ser ainda aprimorados.

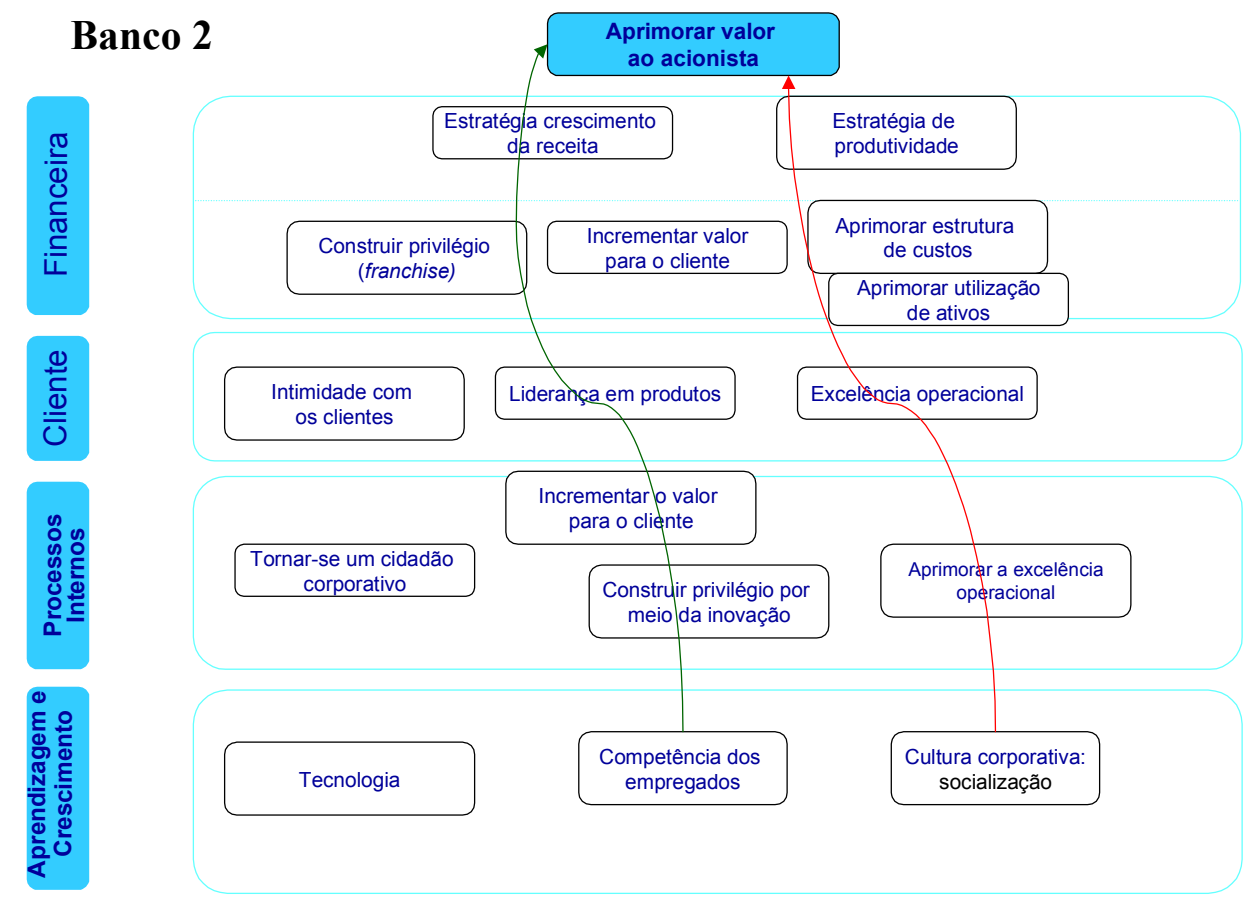

Figura n. ${ }^{\circ} 2$ Mapa estratégico do Banco 2 
3) Intimidade com o cliente, para o Banco 3, evidenciando-se capacidades diferenciais como compreensão e apoio às necessidades do cliente e utilização inteligente da base de dados. Na dimensão de aprendizado e crescimento, sobressaem uma cultura voltada à qualidade, o processo de construção das competências e a contribuição da tecnologia.

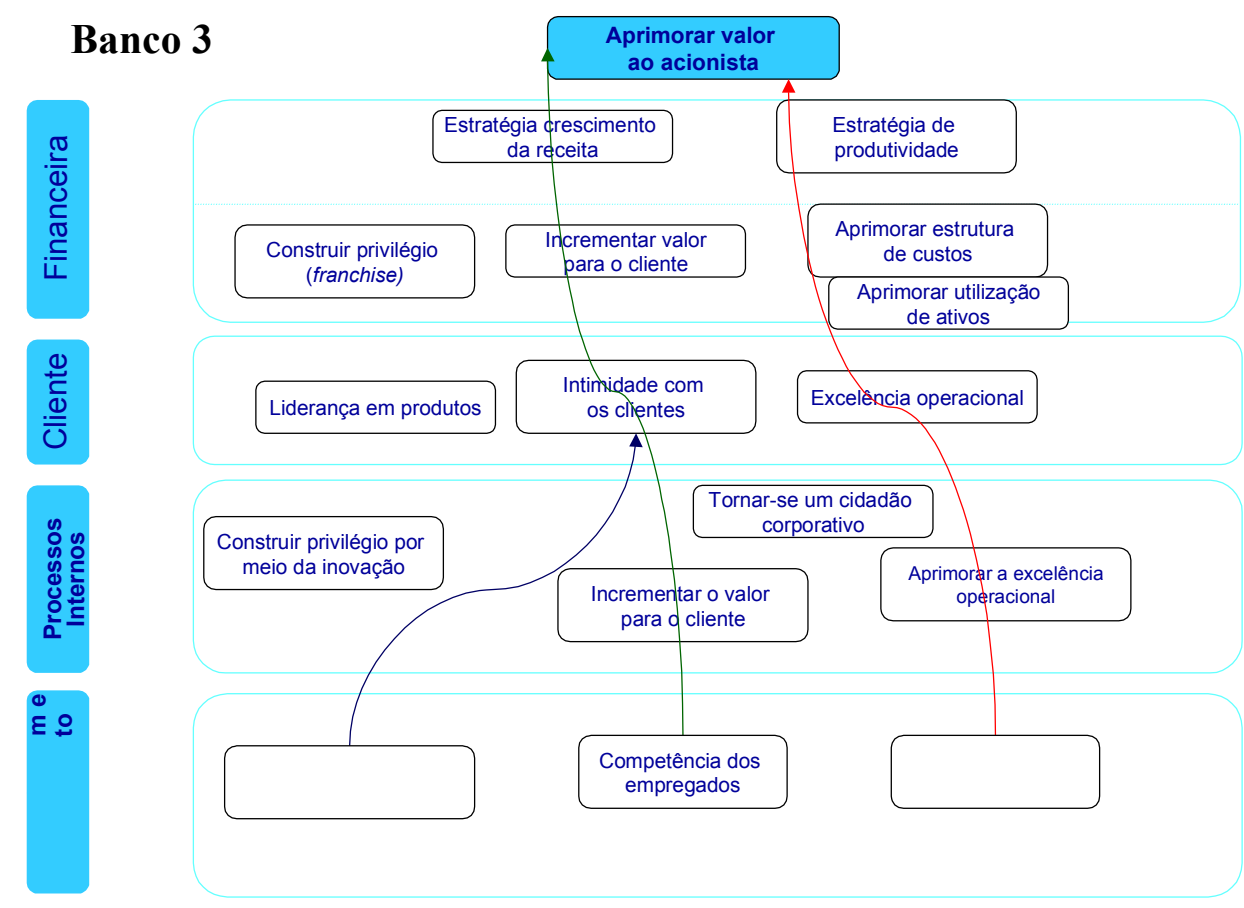

\section{Figura n. ${ }^{\circ} 3$ Mapa estratégico do Banco 3}

Do exame dos mapas, destaca-se a estratégia do Banco 3, a mais robusta, e a do Banco 2. A estratégia do Banco 1 indica disposição de chegar ao patamar dos concorrentes. As capacidades diferenciais que apóiam as proposições de valor são apresentadas em ordem de evidência:

\begin{tabular}{|l|l|l|}
\hline Excelência operacional & Liderança em produtos & Intimidade com o cliente \\
\hline Intenção estratégica de aprender & $\begin{array}{l}\text { Colaboração do pessoal para a } \\
\text { inovação }\end{array}$ & $\begin{array}{l}\text { Compreensão e apoio às } \\
\text { necessidades do cliente }\end{array}$ \\
\hline $\begin{array}{l}\text { Compreensão e apoio às } \\
\text { necessidades do cliente }\end{array}$ & $\begin{array}{l}\text { Compreensão e apoio às } \\
\text { necessidades do cliente }\end{array}$ & $\begin{array}{l}\text { Utilização inteligente da base de } \\
\text { dados }\end{array}$ \\
\hline $\begin{array}{l}\text { Utilização inteligente da base de } \\
\text { dados }\end{array}$ & $\begin{array}{l}\text { Utilização inteligente da base de } \\
\text { dados }\end{array}$ & Intenção estratégica de aprender \\
\hline $\begin{array}{l}\text { Colaboração do pessoal para a a } \\
\text { inovação }\end{array}$ & Intenção estratégica de aprender & $\begin{array}{l}\text { Colaboração do pessoal para a } \\
\text { inovação }\end{array}$ \\
\hline
\end{tabular}

Quadro $\mathrm{n}^{\mathbf{0}}$ 2: Proposições de valor ao cliente e capacidades diferenciais relacionadas 


\section{CONSIDERAÇÕES FINAIS}

Os reflexos das estratégias mapeadas são perceptíveis: Palmeira (2001) apresenta o Banco 2 como o melhor de varejo e o Banco 3 como o melhor de atacado e negócios. Ambos destacados pela rentabilidade e eficiência. Cabe a ressalva de que se está comparando dois bancos de varejo (bancos $1 \mathrm{e}$ 2, que têm bases de mais de 10 milhões de clientes) com um banco com atuação focada em nicho de corporações e clientes de alto poder aquisitivo (Banco 3, que integra um dos maiores grupos financeiros do mundo e pode se enriquecer com o desenvolvimento global de soluções).

Tudo levava a crer que suas práticas sobressaíssem e suas capacidades diferenciais se destacassem.

Por essa razão, optou-se por trabalhar com a ordem de evidência das capacidades em cada organização, e não compará-las diretamente entre si, deixando-se de indicar quem é o melhor ou o pior em determinada capacidade. Se as estratégias e as capacidades são diferentes, a realidade das empresas também o é. O ponto não é salientar qual é a melhor estratégia ou a menos acertada, mas destacar práticas de gestão do conhecimento que concorrem para a formação de capacidades que diferenciam tanto bancos de varejo quanto de atacado.

Percebe-se também que, embora haja vasta literatura sobre gestão do conhecimento, pouco das abordagens teóricas e de aplicação se refletem no dia-a-dia das organizações, que, por vezes, podem até se entusiasmar com as teorias e construir um modelo e divulgá-lo, como no caso do Banco 1. Por outro lado, podem não conhecer muito bem tais teorias, apesar de estar adotando práticas de mensuração como o balanced scorecard, relacionado com administração do conhecimento, sem que as pessoas se percebam gerindo conhecimento, como no caso do Banco 3.

Diante disso, a escolha das teorias esteve adequada à realidade que emergiu da pesquisa, escolhendo-se a análise comparativa de Norton e Kaplan (2001) por estarem relacionados com as práticas visíveis dos bancos estudados, e as abordagens vinculadas com as proposições de valor ao cliente e suas ligações com a gestão do conhecimento (Wiig, 1993; O'Dell e Grayson, 1999). Além de todas as referências pontuais, principalmente aos modelos de Nonaka e Takeuchi (1997) e Nonaka e Konno (1998). E as comparações feitas entre as estratégias de gestão do conhecimento, como as referidas pela American Productivity \& Quality Center APQC (1996): responsabilidade pessoal por conhecimento é a que está mais próxima da do Banco 1; inovação e criação do conhecimento se aproxima da prática do Banco 2 e as ações do Banco 3 estão mais semelhantes a do conhecimento focado no cliente.

Como se pôde constatar, quanto às áreas de ênfase e os benefícios destacados por Wiig (1998), ainda há um longo caminho a se trilhar nas três organizações, mas há efetivamente contribuição das práticas à formação de capacidades. Não foi possível confirmar as perdas pela falta de gerenciamento do conhecimento indicadas por Probst e Knaese (1998).

O estudo corrobora as constatações de Cremer e Meschi (1997), de que as organizações têm um conhecimento intuitivo de suas capacidades efetivas, apesar de integrar a estratégia corporativa e o processo de construção de competências. Outra questão é se as organizações administram deliberadamente suas necessidades de competências que as diferenciam e que permitem que sustentem sua estratégia. Da análise das respostas às perguntas das entrevistas, em nível estratégico, pode-se dizer 
que o Banco 3 é o que está mais próximo de gerir competências. No Banco 1, além do direcionamento para o aprendizado e das ações de treinamento, está-se iniciando uma discussão sobre competências. No Banco 2, não foi possível esclarecer inteiramente como se dá a gestão de competências, no que vai além das ações de treinamento.

$\mathrm{Na}$ análise dos bancos estudados, ficou claro que as práticas relacionadas com gestão do conhecimento cooperam para a formação de quatro das cinco capacidades diferenciais, sendo menos evidente a capacidade "concepção estratégica do negócio". O fato de os dados levantados não permitirem evidenciar a concepção estratégica do negócio merece reflexão, não só por parte dos gestores de pessoas, nas organizações, mas principalmente para as universidades e cursos de pósgraduação, que talvez não estejam contribuindo para a formação das capacidades diferenciais necessárias.

Da pesquisa sobressaiu que a gestão do conhecimento parte de práticas já existentes. O estudo sugere que os mapas estratégicos são úteis para destacar a proposição de valor das organizações e evidenciar a necessidade de buscar o alinhamento estratégico das práticas de gestão do conhecimento organizacional. Essa gestão pró-ativa, chamada de administração estratégica do conhecimento, pode contribuir para criar sinergia.

Quanto às capacidades diferenciais escolhidas, o estudo sugere sua relevância, indicando que sua formação possivelmente contribua para o alcance da vantagem competitiva, uma vez os bancos estudados têm se posicionado à frente de outras organizações e estão entre os líderes do lucrativo setor bancário.

Quanto à questão da sustentabilidade, destaca-se que aspectos culturais são de difícil imitação. De tal forma as capacidades culturais relacionadas com aprender e inovar seriam as mais relevantes, nos quais os bancos 1 e 2 se destacam e estão comparativamente melhor que o Banco 3, em que tais fatores foram os de menor destaque.

Assim, para a indagação principal que norteou este trabalho, é possível concluir que há evidências de que práticas de gestão estratégica do conhecimento organizacional contribuem com a formação de capacidades diferenciais. Foram identificadas ações relacionadas com gestão do conhecimento, bem como evidenciadas ligações teóricas. As constatações permitem sugerir que se gera e evidencia uma relação determinante das práticas de gestão do conhecimento com a formação das capacidades diferenciais. No entanto, ressalve-se que não se trata do único fator determinante, mas apenas um dos fatores.

Finalmente, registradas tais considerações, o desafio da competitividade sustentável nas organizações passa por desenvolver atividades facilitadoras da aplicação do conhecimento, o que envolve mais aspectos culturais, seja desenvolvendo condições capacitantes, seja criando o contexto que propicione a criação e compartilhamento, seja incentivando o aprendizado e a inovação, o que foi constatado no estudo.

\section{RECOMENDAÇÕES}

Finalmente são propostas recomendações que podem ser úteis para outras organizações com características semelhantes. Fica a sugestão de aproveitar a reflexão crítica sobre as ações identificadas e relacionadas com gestão do conhecimento e melhor configurá-las estrategicamente. Muitas práticas colaboram para a formação de capacidades diferenciais, como, por exemplo, intenção estratégica de 
aprender e compreensão e apoio ao cliente e podem significar vantagem competitiva. A contribuição tem possibilidade de ser ainda maior.

Com relação às capacidades diferenciais, recomenda-se atenção gerencial principalmente à “concepção estratégica do negócio" e à "contribuição do pessoal à inovação", que são as capacidades menos evidenciadas. $\mathrm{O}$ que sugere que as práticas de gestão do conhecimento têm contribuído menos com a formação de tais capacidades, o que deve merecer reflexão e ações dos gestores.

Outras recomendações voltam-se à realização de futuros estudos, tanto sobre estratégias de gestão do conhecimento, quanto sobre formação de capacidades diferenciais. Algumas sugestões:

1) Replicar o estudo em outras organizações, de diferentes portes, setores e regiões.

2) Promover estudo mais abrangente, com maior número de empresas, podendo-se empregar inclusive delineamento qualitativo-quantitativo.

3) Restringir o foco de estudos para algumas práticas, como treinamento ou balanced scorecard, e sua integração à estratégia corporativa.

4) Verificar se algumas práticas específicas de gestão do conhecimento contribuem mais que outras com a formação de capacidades diferenciais.

5) Pesquisar se a gestão estratégica do conhecimento pode ser correlacionada a questões como as sugeridas: minimização do risco de perdas de conhecimento, inovações ou maior eficiência organizacional.

Artigo recebido em 06/12/2001. Aprovado em 27/05/2002.

\section{REFERÊNCIAS BIBLIOGRÁFICAS}

ANGELONI, M. T.; FERNANDES, C. B. Organizações de Conhecimento: dos Modelos à Aplicação Prática. In: ENCONTRO DE ESTUDOS ORGANIZACIONAIS ENEO (I : 2000 : Curitiba). Anais. Curitiba: GEO/ANPAD, 2000.

APQC. Knowledge Management: Consortium Benchmarking Study - Final Report. Houston: American Productivity \& Quality Center, 1996.

BARDIN, L. Análise de Conteúdo. Lisboa : Edições 70, 1979.

BRUYNE, P. de. Dinâmica da Pesquisa em Ciências Sociais. Rio de Janeiro: Francisco Alves, 1977.

CARVAlHO, F. J. C. Sistema Bancário e Competitividade: Efeitos da Penetração do Capital Estrangeiro no Setor Bancário Brasileiro. In: COSTA, A. N. C.; ARRUDA, C. A. (org.). Em Busca do Futuro: A Competitividade no Brasil. Rio de Janeiro: Campus, 1999.

CHIESA, V.; MANZINI, R. Competence Levels with Firms: A Static and Dynamic Analysis. In: HEENE, A.; SANCHEZ, R. (Ed.). Competence-Based Strategic Management. West Sussex, UK : John Wiley, p. 195-213, 1997. 
CREMER, E.; MESCHI, P.-X. Integrating Corporate Strategy and Competence-building Processes: A Case Study. In: HEENE, A.; SANCHEZ, R. (Ed.). Competence-Based Strategic Management. West Sussex, UK : John Wiley, p. 215-241, 1997.

DAVENPORT, T. H.; PRUSAK, L. Conhecimento Empresarial: Como As Organizações Gerenciam o seu Capital Intelectual - Métodos e Aplicações Práticas. Rio de Janeiro: Campus, 1998.

DRUCKER, P. F. Prática de Administração de Empresas. Rio de Janeiro: Fundo de Cultura, 1962.

FLEURY, A.; FLEURY, Maria T. L. Estratégias Empresariais e Formação de Competências. São Paulo: Atlas, 2000.

GEUS, A. de. A Empresa Viva: Como as organizações podem aprender a prosperar e se perpetuar. Rio de Janeiro: Campus, 1998.

GRANT, R. M. Prospering in Dynamically Competitive Environments: Organizational Capability as Knowledge Integration. In: ZACK, M. H. (ed.) Knowledge and Strategy: resources for the knowledge-based economy. Woburn, MA : Butterworth-Heinemann, p. 133-153, 1999.

HALL, R. Complex Systems, Complex Learning, and Competence Building. In: SANCHEZ, R.; HEENE, A. (ed.). Strategic Learning and Knowledge Management. West Sussex : John Wiley, p. 39-64, 1998.

. The Strategic Analys of Intangible Resources. In: ZACK, Michael H. (ed.) Knowledge and Strategy: resources for the knowledge-based economy. Woburn, MA : Butterworth-Heinemann, p. 181-195, 1999.

HAMEl, G.; PRAhalad, C. K. Competindo Pelo Futuro: Estratégias inovadoras para obter o controle do seu setor e criar os mercados de amanhã. Rio de Janeiro: Campus, 1997.

HANSEN, M. T., NOHRIA, N. e TIERNEY, T. What's Your Strategy For Managing Knowledge? Harvard Business Review, Boston, vol. 77, no. 2, p. 106-116, March-April 1999.

KAPLAN, R. S. e NORTON, D. P. A Estratégia Em Ação: Balanced Scorecard. Rio de Janeiro : Campus, 1997.

176, September-October, 2000.

. Having Trouble with your Strategy? Then Map It. Harvard Business Review, p. 167-

; _. The Strategy-Focused Organization: how Balanced Scorecard companies thrive in the new business environment. Boston: Harvard Business School Press, 2001.

LALANE, B. L'essentiel du Management. Executive Digest. Ano 4, n. 48, p. 31-52, outubro 1998.

MARSHALL, C.; PRUSAK, L.; SHPILlBERG, D. Financial Risk and the Need for Superior Knowledge Management. In: PRUSAK, Laurence. Knowledge in Organizations. Newton, MA : Butterworth-Heinemann, 1997.

McGILL, M. E.; SLOCUM, J. W, Jr. A Empresa mais Inteligente. Rio de Janeiro: Campus, 1995. 
MEISTER, J. C. Educação Corporativa: a Gestão do Capital Intelectual através da Universidades Corporativas. São Paulo : Makron, 1999.

NONAKA, I.; TAKEUCHI, H. Criação De Conhecimento Na Empresa: Como as empresas japonesas geram a dinâmica da inovação. Rio de Janeiro : Campus, 1997.

NONAKA, I.; KONNO, Noburo. The Concept of "Ba": Buildind a Foundation for Knowledge Creation. California Management Review. Berkeley,Vol. 40, no. 3, p. 40-54, Spring, 1998.

O'DELL, C.; GRAYSON, C. J., Jr. Knowledge Transfer: Discover your value proposition. Strategy \& Leadership. Vol. 27, issue 2, p. 10-15, Mar/Apr. 1999.

PALMEIRA, C. Ranking dos Bancos: os melhores do Brasil. Conjuntura Econômica. V. 55, n. 11, novembro 2001.

PINCHOT, G.; PINCHOT, E. O Poder das Pessoas: Como usar a Inteligência de Todos Dentro da Empresa para Conquista de Mercado. Rio de Janeiro : Campus, 1995.

PORTER, M. E. A Vantagem Competitiva das Nações. In: MONTGOMERY, Cynthia A.; PORTER, M. E. (org.) Estratégia: A Busca da Vantagem Competitiva. Rio de Janeiro : Campus, 1998.

PRAHALAD, C. K.; RAMASWAMY, V. Co-opting customer competence. Harvard Business Review, Boston, vol. 78, no. 1, p. 79-87, January-February 2000.

PROBST, G. J. B.; KNAESE, B. Risikofaktor Wissen: Wie Banken sich vor Wissensverlusten schützen. Wiesbaden : Gabler, 1998.

SCHUCK, G. Tecnologia inteligente, operários inteligente. In: STARKEY, K. (Ed.). Como as Organizações Aprendem. São Paulo : Futura, 1997.

SIVULA, P.; van den BOSCH, F. A. J.; ELFRING, T. Competence Building by Incorporating Clients into the Development of a Business Service Firm's Knowledge Base. In: SANCHEZ, R.; HEENE, A. (ed.). Strategic Learning and Knowledge Management. West Sussex : John Wiley, 1998.

STEWART, Thomas A. Capital Intelectual: A nova vantagem competitiva das empresas. Rio de Janeiro : Campus, 1998.

THUROW, L. C. Building Wealth: the new rules for individual, companies, and nations in a Knowledge-Based Economy. New York : HarperCollins, 1999.

TREACY, M. e WIERSEMA, F. A Disciplina dos Líderes de Mercado. Rio de Janeiro: Rocco, 1995.

UHRY, R. Gestão Estratégica do Conhecimento Organizacional e Formação de Capacidades Diferenciais. Curitiba, 2001. Dissertação (Mestrado em Administração). Centro de Pesquisa e PósGraduação em Administração. Universidade Federal do Paraná.

VENZIN, M.; von KROGH, G.; ROOS, J. Future Research into Knowledge Management. In: von KROGH, G.; ROOS, J.; KLEINE, D. (ed.). Knowing in Firms. London: Sage, 1998. 
von KROGH, G.; ROOS, J. Organizational Epistemology. New York: St. Martin's Press, 1995. 2001 .

; ICHIJO, K.; NONAKA, I. Facilitando a Criação de Conhecimento. Rio de Janeiro: Campus,

WIIG, K. M. Knowledge Management Foundations - Thinking about Thinking - How People and Organizations Create, Represent, and Use Knowledge. Arlington: Schema, 1993.

. Gestão Estratégica do Conhecimento: de onde veio e para onde vai? Empresas \& Tendências, v. $5, \mathrm{n}^{\circ} 48$, p. 6-18, agosto 1998 .

YIN, R. K. Case Study Research. Newbury Park : Sage, 1989.

ZAHN, E.; FOSCHIANI, S.; TILEBEIN, M. Nachhaltige Wettbewerbsvorteile durch Wissensmanagement. In: KRALLMANN, H. (Hrsg.). Wettbewerbsvorteile durch Wissenmanagement. Stuttgart: Schäffer-Poeschel, p. 239-270, 2000.

ZARIFIAN, P. Objectif compétence: pour une nouvelle logique. Paris: Liaisons, 1999. 